\title{
A Spatial Analysis of Serotine Bat (Eptesicus serotinus) Roost Location and Landscape Structure: A Case Study in Sussex, UK
}

\author{
Michael Tink, ${ }^{1}$ Niall G. Burnside, ${ }^{1}$ and Stephen Waite ${ }^{2}$ \\ ${ }^{1}$ Biogeography \& Ecology Group, School of Environment \& Technology, University of Brighton, Brighton, UK \\ ${ }^{2}$ Writtle College, Chelmsford, Essex, UK \\ Correspondence should be addressed to Niall G. Burnside; n.g.burnside@brighton.ac.uk
}

Received 9 September 2013; Accepted 17 November 2013; Published 21 January 2014

Academic Editor: Antonio Terlizzi

Copyright (C) 2014 Michael Tink et al. This is an open access article distributed under the Creative Commons Attribution License, which permits unrestricted use, distribution, and reproduction in any medium, provided the original work is properly cited.

\begin{abstract}
Roost location is a key factor affecting the survival and fitness of British bats. It has been suggested that a knowledge and understanding of the factors which may influence the selection of roost location are fundamental to conservation efforts. Our study aims to investigate the relationship between Eptesicus serotinus roost location and landscape structure. The study is based in the Sussex region of South East England. The landscape characteristics of 97 roosts locations were compared against 100 random control locations. Habitat analysis was carried out at three distance bands and included an analysis of roost density. The results indicate that $E$. serotinus is selective in locating roosts. The study demonstrates that there are significant differences between the landscape composition surrounding roost sites and the wider landscape. In particular, E. serotinus roost sites are found to be located in areas with a significantly higher cover of arable land and improved grassland. Kernel density analysis was successfully used as an additional method to the direct comparison of roost neighbourhood composition. Density analysis identified the location and characteristics of possible centres of E. serotinus activity. It is anticipated that the findings will enable the needs of bats to be considered in future landscape conservation initiatives and development policies.
\end{abstract}

\section{Introduction}

Studies have shown that bat species occurrence and breeding success can be negatively affected by anthropogenic changes to landscapes (e.g., [1-4]). All British bat species have experienced some level of population decline in recent years [5], with the loss of roosting and foraging habitat thought to be among the most important causes $[1,6]$. Landscape changes can negatively affect biodiversity and individual species distribution patterns [7] and lead to decreased bat populations [3]. As $K$-strategists, bat populations would be expected to remain fairly constant, and low intrinsic growth rates would mean that recoveries following a decline could prove lengthy [8]. Although all British bats and their roosts are protected by UK legislation and EU law, protection is not extended to foraging sites. This leaves bats vulnerable to landscape change [9] and has prompted some authors to comment that protection of roosts is of limited value without simultaneous protection of the surrounding habitat and prey base $[2$, 10]. Knowledge of individual species habitat requirements is essential for developing appropriate management plans for protecting foraging habitats and ultimately the successful conservation of bat species.

The expansion and intensification of agricultural land has been the predominant driver of habitat loss in the UK, with urbanization also important [11]. Such patterns of change are evident in the study region [12]. The intensification of farming has initiated loss and fragmentation of habitats [13] and has been associated with losses of biodiversity on farmland [14-16]. In an attempt to reverse this loss of farmland biodiversity, agrienvironment schemes (AES) are tailored to local wildlife and landscape needs and should endeavor to take the requirements of bats into account.

Roost location is a key factor in determining the survival and fitness of British bats; thus knowledge of the factors influencing roost selection is fundamental to bat species conservation efforts [17]. While Kerth et al. [18] argue that the underpinning reasons for roost selection by bats are "somewhat speculative," Bihari [19] proposes that the two key factors are the availability of suitable roosts and the presence 
of foraging habitat. The availability of suitable roosts is not thought to be a limiting factor for synanthropic bats [20], suggesting that for such species the presence of foraging habitat nearby is paramount in roost selection. Indeed previous studies in the UK have established relationships between the presence of roosts and the surrounding habitat. In comparison to randomly selected control buildings, serotine bat Eptesicus serotinus roosts are closer to woodland (particularly broadleaved woodland), water, and pasture and have higher proportions of improved grassland within $1 \mathrm{~km}[21,22]$. Brown long-eared bat Plecotus auritus roosts are located closer to woodland and water, with a greater proportion of woodland within $0.5 \mathrm{~km}$ and more connections through linear features, compared to random points [23, 24]. Pipistrelle bat Pipistrellus pipistrellus roosts are closer to water and deciduous woodland, have more linear features leading away from them, and have larger proportions of deciduous and coniferous woodland within $0.5 \mathrm{~km}$, compared to randomly selected buildings $[25,26]$. While relationships between bat roosts and deciduous or mixed woodland have been identified, studies have consistently reported little evidence of bats foraging in coniferous woodlands [27-29]. Linear landscape features are known to be important for bats during transit and foraging flights [30, 31]; however their importance in roost selection is less clear.

The research presented in this paper is concerned with E. serotinus roosts, which are almost exclusively located in buildings [32, 33]. Feeding predominately on Lepidoptera, Coleoptera, and Diptera, [34-36], E. serotinus' main foraging habitats are grazed pasture, meadows, streetlights, and woodland edge, with the use of downland, gardens, hedgerows, and areas surrounding water also reported [34, 37-39]. Radio tracking studies have shown that foraging is usually concentrated within $4.5 \mathrm{~km}$ of the roost [38], although most individuals will concentrate their hunting to more localised areas closer to the roost [34].

The relationship between E. serotinus and linear features is unclear. Verboom and Huitema [40] found that activity decreases as distance from a linear feature increases and increases as the density of linear features increases. It has also been observed that forage sites are commonly connected by linear features [34, 36, 41], with Brandt et al. [42] suggesting that deciduous and mixed woodland edges are perhaps the most important linear features for the species. In contrast, Boughey et al. [31] found no relationship between E. serotinus activity and density of linear features, and Battersby [21] found no evidence of increased linear features surrounding roosts compared to control buildings.

Studies analysing flight paths and the diet of E. serotinus have concluded that by foraging over a diverse range of habitat types, they exploit whatever habitat is available, and therefore the presence of specific forage habitat close to the roost is probably not critical [38]. Where there is no suitable forage close to the roost, the bat will commute further distances until a suitable area is found [43].

By investigating differences in the habitat surrounding roosts compared to control buildings, the present study seeks to explore the relationships between roost location and habitat availability at varying distances from the roost.
Geographic Information Systems (GIS) and spatial statistics were used to analyse the composition of habitats surrounding roosts and the distance to selected habitat features at varying spatial scales.

\section{Materials and Methods}

2.1. Study Area. The study focused on the counties of East and West Sussex in South East England. The study area is approximately $3800 \mathrm{~km}^{2}$, encompassing different geological regions with distinct habitat features associated with Weald and South Downs. Though fragmented by urban areas and agricultural land, a patchwork of large woodland areas is present in the Low Weald. In contrast the High Weald is comprised of extensive and relatively well-connected, areas of woodland, with the Downs largely covered by arable land and pasture.

2.2. Data. Data on the location of E. serotinus roosts was provided by Sussex Biodiversity Records Centre, with details of additional maternity roosts provided by the Sussex Bat Group. Only roosts that were known to have been used since the year 2000 were included in the study. Although $E$. serotinus displays a high level of roost fidelity, recent studies had shown that a number of sites were not recently occupied [32]. A total of ninety-seven roosts were included in the study. Fifteen of ninety-seven roosts were recognised as maternity roosts, whilst the remaining eighty-two were unspecified summer roosts. Hibernacula $(n=1)$ were excluded from the analysis, as they serve different purposes to summer roosts and are therefore unlikely to be selected using the same criteria.

For habitat analysis the Land Cover Map (LCM) 2000, developed by the Centre for Ecology and Hydrology (CEH), was used. In LCM 2000, 25 metre resolution satellite images, from the Landsat Thematic Mapper and the Indian Remote Sensing Satellite, have been classified into seventy-two habitat variant classes [44]. Comparison of the LCM 2000 data with field studies shows that the LCM 2000 data has 85\% accuracy [44].

In order to compare the habitat surrounding roosts with the landscape as a whole, 100 randomly selected control points were generated within the study area using Hawths tools [45]. In order to eliminate bias and ensure the control points were not in locations where E. serotinus would not be selected as a roost, the random points were moved to the centre of the nearest building using OS 1:10000 maps. The use of a large number of sample points has not been used in previous studies of E. serotinus, which, with the exception of Boughey et al. [22] who included 91 samples, have been limited to sample sizes between 2 and 39 (e.g., [21, 34, 35, 38, 41, 43]).

2.3. Exploratory Spatial Data Analysis. Analysis of roost clustering was performed with average nearest neighbour analysis in ESRI ArcMap 9.3, using Euclidean distances. By only using distance to the closest point, the average nearest neighbour technique is restricted to consider only the smallest scales of pattern, overlooking larger scales 
of pattern [46]. Therefore Multi-Distance Spatial Cluster Analysis, based upon Ripley's $K$-function, was also carried out to test for clustering at a range of distances up to the maximum reported forage commute of $12 \mathrm{~km}$ [38]. Roost densities were also calculated. No gold standard technique has been established for estimating density parameters, and it is often a fairly subjective process. Several different methods have been defined (e.g., [46-48]), with Williamson et al. [47] arguing that many approaches are arbitrary in nature, with no consideration of the spatial distribution of points. The $k$-nearest approach [47] attempts to overcome these issues by using the expected mean distances between points as the search radius. Density maps were produced using observed mean distances and a range of search radii from roosts based on the species autecology. The $k$-nearest neighbour approach produced the most robust and consistent outputs and is presented in this paper.

2.4. Habitat Analysis. Habitat analysis was carried out in three stages, measuring relationships between roosts and habitat features previously associated with E. serotinus (arable land, improved grassland, unimproved grassland, urban areas, deciduous woodland, coniferous woodland, and total woodland). Firstly distance to the selected features was calculated, followed by analysis of habitat composition using two spatial scales; habitat composition surrounding individual roosts; and habitat composition at roost hotspots.

2.5. Distance to Habitat Features. A combination of LCM 2000 data, 1:10000 Ordnance Survey Maps, and Google Map images [49] were used to identify proximity to habitat features. The distance to the nearest of each feature was measured as a straightline distance using ESRI ArcMap 9.3, for both roosts and controls. Mann Whitney $U$ tests were run to search for differences between the two groups.

2.6. Habitat Composition Surrounding Roosts. Multiple-ring buffer zones, set at $0-0.5 \mathrm{~km}, 0.5-1.5 \mathrm{~km}$, and $1.5-4.5 \mathrm{~km}$, around individual points were created in ESRI ArcMap 9.3. These ranges were selected so that habitats important at a more localised scale were included, as well as those habitats within the forage range. The maximum distances were selected to conform to published estimates of distances travelled from roosts as outlined in the introduction, and the inclusion of a $0-0.5 \mathrm{~km}$ zone was in line with other previously undertaken similar studies (e.g., [22, 23, 25]). The number of patches of each habitat was recorded, and habitat diversities were calculated using the Shannon index. To test the effect of woodland fragmentation, Euclidean average nearest neighbour ratios between woodland patches were also calculated. Mann Whitney $U$ tests (or 2 sample $t$-tests where the data were normally distributed) were used to test for differences between roosts and controls.

2.7. Land Use at Hotspots. In an effort to examine the relationship between roost location and landscape structure, an analysis of bat roost density was undertaken. Density surfaces were calculated, using roost locations, via a kernel density estimation method [47]. A classification of "Hotspots" was
TABLE 1: Exploratory spatial data analysis summary table including average nearest neighbour analysis $(\mathrm{m})$ and maximum point density (points per $\mathrm{km}^{2}$ ).

\begin{tabular}{lcc}
\hline Number of points & $\begin{array}{c}\text { Roosts } \\
97\end{array}$ & $\begin{array}{c}\text { Controls } \\
100\end{array}$ \\
\hline Average nearest neighbour analysis & & \\
Observed mean distance $(\mathrm{m})$ & 2549.2 & 3589.7 \\
Expected mean distance $(\mathrm{m})$ & 3098.2 & 3395.6 \\
Nearest neighbour ratio & 0.82 & 1.06 \\
$P$ value & $<0.001$ & 0.27 \\
Clustering classification & Clustered & Random \\
Maximum density (points per $\mathrm{km}^{2}$ ) & 0.33 & \\
\hline
\end{tabular}

created by dividing roost densities (see Section 2.1) into quartiles, with those that were in the top quartile (Q4) of densities classified as roost hotspots, and those in the bottom quartile (Q1) labelled low density areas.

Using the density surface estimation, 100 randomly selected $1 \mathrm{~km}^{2}$ sample areas (quadrats) were selected from the mapped areas identified as roost hotspots (Q4). A further 100 randomly selected sample areas $\left(1 \mathrm{~km}^{2}\right)$ were selected from low density areas (Q1). The habitats composition within these sample areas was then compared using a Mann Whitney $U$ test.

All data were tested for normality and found to have a nonnormal distribution; log transformation was attempted but in $80 \%$ of cases data remained nonnormal. Therefore, nonparametric tests were applied to the original untransformed data. In all cases, a Bonferroni correction for multiple comparisons was used to assess the data collected in both the habitat and density analysis. Bonferroni correction provides a safeguard against multiple tests of statistical significance on the same data falsely giving the appearance of significance [50]. Bonferroni correction was calculated by $\alpha / n$.

\section{Results}

3.1. Exploratory Spatial Data Analysis. Roosts were significantly clustered (Table $1 ; P<0.001$ ) with expected mean distances between roosts larger than the observed mean distance. The random distribution of the control points was confirmed by lack of a significant difference in the observed mean distances and expected mean distances between points (Table 1; $P=0.27$ ). Multi-Distance Spatial Cluster Analysis showed that this relationship was consistent at multiple distances from roosts, with little variation in the difference between observed and expected mean distances at different scales (Figure 1). Using the Average Nearest Neighbour expected mean distance as a search radius, maximum roost densities of 0.33 roosts per $\mathrm{km}^{2}$ were observed in the centre of Sussex (Figure 2).

3.2. Habitat Analysis, Distance to Habitat Features. To address the issue of multiple comparisons in the analysis of distance to habitat features a Bonferroni correction was used. For nine comparisons between roosts and controls $P<$ 0.00111 was required for $\alpha=0.01 ; P<0.005$ was required for 


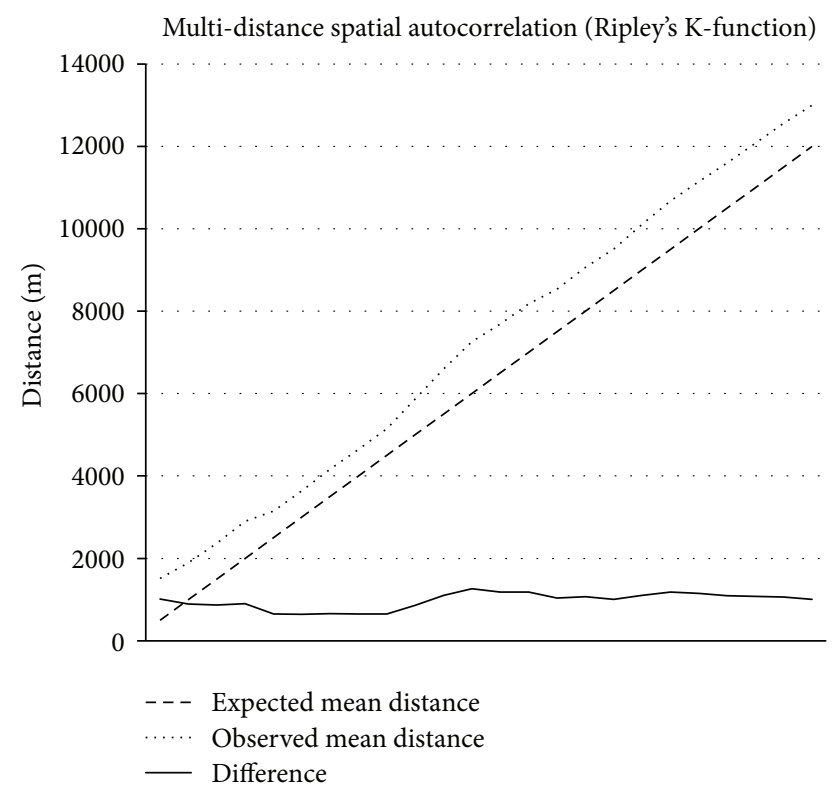

FIGURE 1: The pattern of average nearest neighbour between points measured at multiple scales. The difference between the expected mean distance (dashed line) and observed mean distance (dotted line) remains fairly constant across the $12 \mathrm{~km}$ measured (solid line).

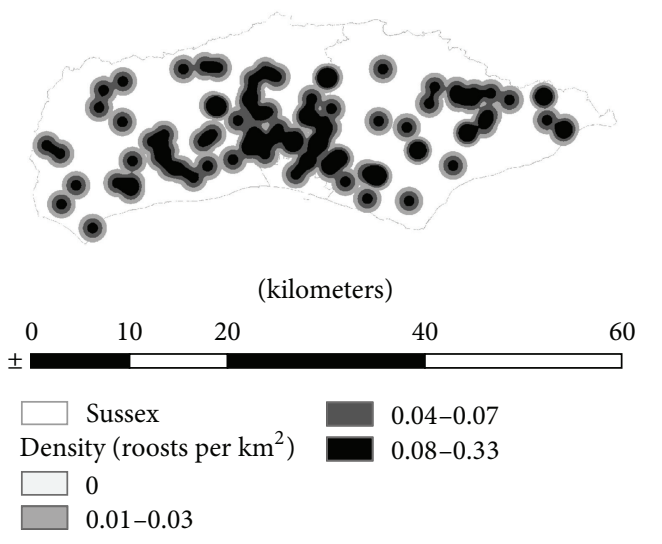

FIGURE 2: Kernel density estimation (KDE) of Eptesicus serotinus roosts in the Sussex region, South East England, using a $k$-nearest search radius approach $(k=3098 \mathrm{~m}) \cdot n=97$. Legend uses a quartiles classification.

$\alpha=0.0556$. The analysis showed that there were no significant differences between the recorded distances to multiple habitat features from either roost locations or control buildings (see Table 2).

3.3. Habitat Composition Surrounding Roosts. To address the issue of multiple comparisons in the analysis of habitat composition surrounding roosts a Bonferroni correction was used. For fifteen comparisons at each distance $P<0.000667$ was required for $\alpha=0.01 ; P<0.00333$ was required for $\alpha=0.05$.

The analysis showed that within the $0-0.5 \mathrm{~km}$ buffer zone the selected habitats were not found to differ significantly between roost locations and controls. Analysis in the 0.5$1.5 \mathrm{~km}$ buffer zone identified two variables that differed significantly between roost locations and control locations. The number of arable patches (Table 3; $P=0.0018$ ) and total number of woodland patches (Table $3 ; P=0.0001$ ) were both significantly higher surrounding roosts compared to controls (see Table 3).

Within the $1.5-4.5 \mathrm{~km}$ buffer zone a significantly higher percentage cover of improved grassland (Table $3 ; P=0.0017$ ) and arable land (Table $3 ; P=0.0034$ ) was found in the landscape surrounding roost locations. Although the arable land was only found to be significant at $\alpha=0.10$ $(P<0.00588$ was required if adjusted via the Bonferroni correction). Interestingly, and in contrast to the $0.5-1.5 \mathrm{~km}$ buffers, where the number of woodland patches was higher surrounding roosts, the $1.5-4.5 \mathrm{~km}$ buffer zone showed that the number of woodland patches was significantly higher in areas surrounding controls (Table 3; $P=0.0002$ ). This may, in part, be associated with the increased number of coniferous patches surrounding controls $(n=34)$ compared to roosts ( $n=23)$, but this difference was not found to be significant (Table 3; $P=0.0327$ ).

Finally Euclidean average nearest neighbour ratios for woodland were significantly lower at roosts within the $1.5-4.5 \mathrm{~km}$ buffers, indicating a significantly more clustered woodland pattern of distribution surrounding roosts (Table 3; $P<0.0001$ ). Despite the significant differences between the landscape structure associated with roosts and control locations at mid and large buffer ranges, the overall landscapes did not differ in terms of habitat diversity (Table 3).

3.4. Land Use at Hotspots. To address the issue of multiple comparisons in the analysis of habitat composition within density hotspots a Bonferroni correction was used. For sixteen comparisons between $Q 4$ and $Q 1, P<0.000625$ was required for $\alpha=0.01$ and $P<0.00313$ was required for $\alpha=0.05$.

In areas of low roost density, a significantly higher percentage of coniferous woodland (Table $4 ; P<0.0001$ ) was observed. Equally, the number of patches of coniferous woodland (Table 4; $P<0.0001$ ) and urban land (Table 4; $P<0.0001)$ was higher in areas of low roost density. Euclidean average nearest neighbour ratios for woodland patches were greater than 1 in both groups indicating a dispersed distribution, with a higher ratio at roost hotspots (Table 4; $P=0.0048)$. Although this was only significant at $\alpha=0.10$ $(P<0.00625$ was required if adjusted using the Bonferroni correction) but may infer a more dispersed woodland distribution in areas of high bat roost density.

\section{Discussion}

4.1. Roost Distribution. A significantly clustered distribution was observed amongst roosts, suggesting that E. serotinus is indeed selective in choosing roost location, rather than choosing locations randomly throughout the landscape. This finding is consistent with studies of other bat species, which have identified that roost selection was nonrandom (e.g., [2325]). Roost densities peaked at 0.33 roosts per $\mathrm{km}^{2}$, with the 
TABLE 2: Comparison between roost $(n=97)$ and control $(n=100)$ of distances (metres) to landscape features. Adjusted using Bonferroni correction for nine comparisons between roosts and controls.

\begin{tabular}{|c|c|c|c|}
\hline & \multicolumn{3}{|c|}{ Median } \\
\hline & Roost & Control & $P$ value \\
\hline Distance to linear feature $>100 \mathrm{~m}(\mathrm{~m})$ & 22 & 32 & 0.030 \\
\hline Distance to arable land (m) & 60 & 65 & 0.727 \\
\hline Distance to improved grassland (m) & 70 & 50 & 0.333 \\
\hline Distance to unimproved grassland (m) & 349 & 242 & 0.261 \\
\hline Distance to deciduous woodland (m) & 138 & 177 & 0.310 \\
\hline Distance to coniferous woodland (m) & 899 & 830 & 0.588 \\
\hline Distance to woodland (m) & 160 & 182 & 0.339 \\
\hline Distance to urban areas (m) & 919 & 1011 & 0.817 \\
\hline Distance to water (m) & 270 & 283 & 0.681 \\
\hline
\end{tabular}

$P<0.00111$ is required for $\alpha=0.01^{* * *} ; P<0.00556$ is required for $\alpha=0.05^{* *}$.

TABLE 3: Comparison of habitat composition between roosts $(n=97)$ and controls $(n=100)$ using ring buffer analysis. Adjusted using Bonferroni correction for fifteen comparisons at each distance.

\begin{tabular}{|c|c|c|c|c|c|c|c|c|c|}
\hline \multirow{2}{*}{ Landscape parameters } & \multicolumn{3}{|c|}{$0-0.5 \mathrm{~km}$ buffer } & \multicolumn{3}{|c|}{$0.5-1.5 \mathrm{~km}$ buffer } & \multicolumn{3}{|c|}{$1.5-4.5 \mathrm{~km}$ buffer } \\
\hline & Roost & Control & $P$ value & Roost & Control & $P$ value & Roost & Control & $P$ value \\
\hline$\%$ Arable land & $23.3 \%$ & $25.8 \%$ & 0.7785 & $31.5 \%^{\dagger}$ & $27.2 \%^{\dagger}$ & 0.033 & $31.9 \%$ & $26.6 \%$ & $0.0034^{*}$ \\
\hline$\%$ Improved grassland & $26.6 \%$ & $27.3 \%$ & 0.6251 & $28.2 \%^{\dagger}$ & $24.0 \%^{\dagger}$ & 0.014 & $27.6 \%$ & $24.3 \%$ & $0.0017^{* *}$ \\
\hline$\%$ Unimproved grassland & $1.7 \%$ & $1.8 \%$ & 0.8922 & $2.5 \%$ & $2.5 \%$ & 0.749 & $2.7 \%$ & $2.6 \%$ & 0.9791 \\
\hline$\%$ Urban areas & $7.2 \%$ & $4.0 \%$ & 0.1376 & $5.5 \%$ & $6.9 \%$ & 0.2703 & $6.1 \%$ & $7.9 \%$ & $0.0223^{*}$ \\
\hline \% Deciduous woodland & $14.4 \%$ & $10.9 \%$ & 0.1859 & $15.0 \%$ & $15.6 \%$ & 0.9174 & $15.6 \%$ & $19.4 \%$ & 0.3253 \\
\hline$\%$ Coniferous woodland & $0.0 \%$ & $0.0 \%$ & 0.8685 & $0.3 \%$ & $0.7 \%$ & 0.0881 & $0.9 \%$ & $1.6 \%$ & 0.0596 \\
\hline$\%$ Total woodland & $14.4 \%$ & $12.4 \%$ & 0.2316 & $16.2 \%$ & $17.9 \%$ & 0.9731 & $17.1 \%$ & $21.7 \%$ & 0.2763 \\
\hline Arable land patch number & 9 & 8 & 0.8731 & 67 & 53 & $0.0018^{* *}$ & 503 & 492 & 0.6417 \\
\hline Improved grassland patch number & 9 & 9 & 0.3118 & 58 & 52 & 0.1112 & 422 & 470 & 0.0269 \\
\hline Urban areas patch number & 3 & 2 & 0.1177 & 20 & 19 & 0.3043 & 165 & 194 & 0.0525 \\
\hline Deciduous woodland patch number & 6 & 5 & 0.1472 & 36 & 34 & 0.5797 & 274 & 295 & 0.3001 \\
\hline Coniferous woodland patch number & 0 & 0 & 0.7997 & 2 & 3 & 0.1072 & 23 & 34 & 0.0327 \\
\hline Total woodland patch number & 7 & 6 & 0.4558 & 58 & 43 & $<0.0001^{* * *}$ & 308 & 416 & $0.0002^{* *}$ \\
\hline Shannon diversity index & 0.263 & 0.263 & 0.983 & $0.236^{\dagger}$ & $0.232^{\dagger}$ & 0.665 & 0.241 & 0.236 & 0.783 \\
\hline Woodland ANNR & 1.805 & 1.701 & 0.103 & 1.075 & 1.063 & 0.929 & 0.862 & 0.933 & $<0.0001^{* * *}$ \\
\hline
\end{tabular}

$P<0.000667$ is required for $\alpha=0.01^{* * *} ; P<0.00333$ is required for $\alpha=0.05^{* *}$; and $P<0.00667$ is required for $\alpha=0.10^{*}$.

Key to symbols: ${ }^{\dagger}$ mean used instead of median. Woodland ANNR: woodland Euclidean average nearest neighbour ratio.

TABLE 4: Composition of habitats composition at roost density hotspots (Q4) and areas of low roost density (Q1).

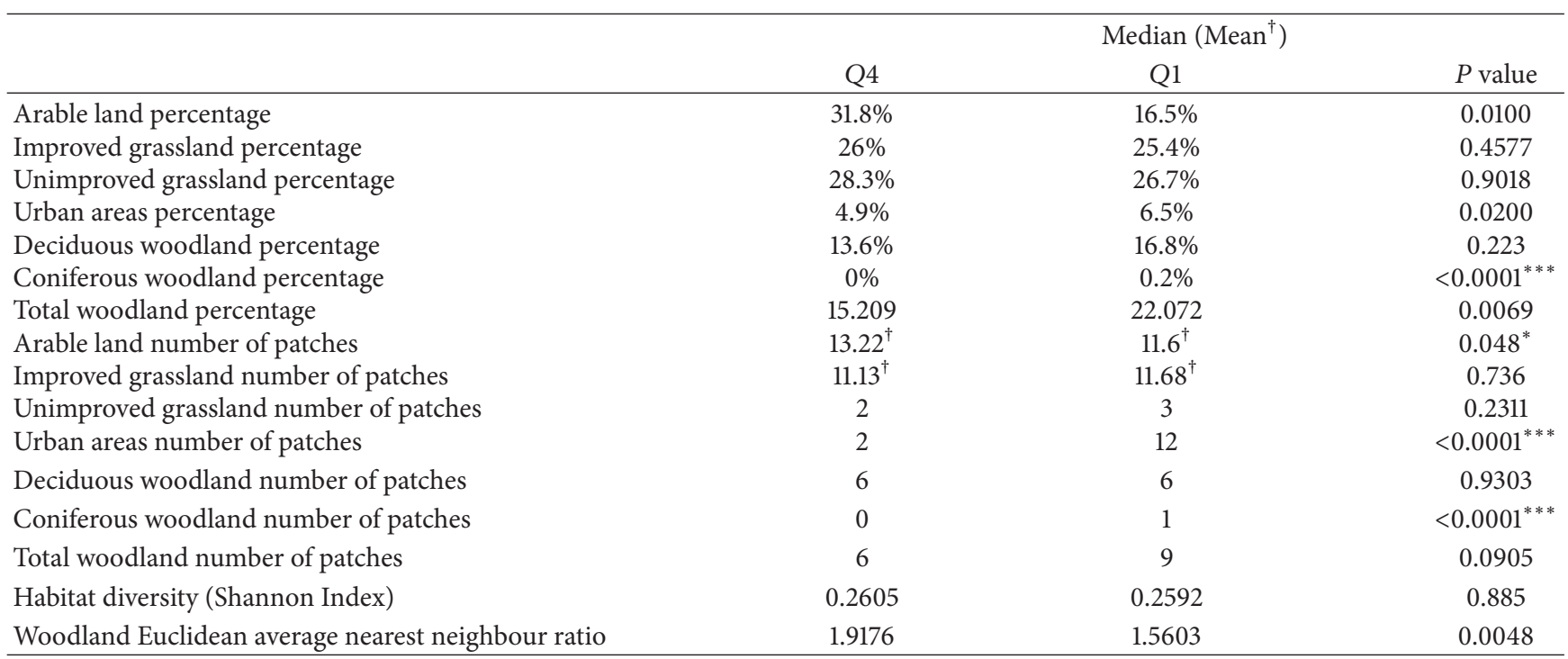

Key to symbols: ${ }^{\dagger}$ mean used instead of median. Adjusted using Bonferroni correction for sixteen comparisons between Q4 and Q1.

$P<0.000556$ is required for $\alpha=0.01^{* * *} ; P<0.00278$ is required for $\alpha=0.05^{* *}$. 
roost location data showing that there are large areas of high roost density in central Sussex. Previous attempts at measuring density in bats have focused on bat population density, rather that roost density (e.g., [34, 51, 52]). Bat population data were not available in the present study, so comparisons between roost and population estimates were not possible. There are many difficulties in measuring bat distribution and density [34], and there is limited knowledge of population structures in most bat species [53]. Without additional survey effort it is not possible to determine whether the data used in this study represent a substantial underestimate of roosts density and include false negatives, so some caution must be exercised when interpreting this part of the study.

4.2. Distance to Landscape Features. Compared to controls, roosts were not found to be significantly different in their distance to the landscape features examined. While this offers support to the work of Battersby [21] and Boughey et al. [22], who also did not find significant differences, other workers found that E. serotinus activity decreased as distance from linear features increased (e.g., [40]). The contrasting findings are possible due to the differing methods used in measuring the relationship. Verboom and Huitema [40] and Boughey et al. [22] analysed the relationship between E. serotinus activity and density of linear features, while Battersby [21] tested differences between the distance to linear features from roost compared to control points, similar to the present study. The prevailing regional landscape, for example, predominant form of land management, may also affect the likelihood for finding a positive or negative association between roosts and linear features. Furthermore this may highlight differences between the species in the UK and mainland Europe, with similar finding in the present study and other UK studies $[21,22]$, but contrasting findings from the Netherlands [40].

4.3. Habitat Composition Surrounding Roosts. Analysis using $0-0.5 \mathrm{~km}$ buffers showed that, at distances of 500 metres or less from roosts, no significant differences were found between roosts and control locations. This close range assessment was considered important given recent suggestions that habitat close to the roost may be more effective in predicting roost presence than the habitats associated with forage range [22]. Our study did not support this assertion.

At distances greater than 500 metres from roosts, however, significant differences were detected between roosts and control locations. For example, within the $0.5-1.5 \mathrm{~km}$ buffer areas the number of patches of arable land was higher surrounding roosts. Furthermore, in the $1.5-4.5 \mathrm{~km}$ buffer area the percentage cover of arable land was significantly higher surrounding roosts. These observations support the finding of previous studies that have found similar associations between E. serotinus and this habitat (e.g., [21, 34, 38]).

At the largest buffer radius $(1.5-4.5 \mathrm{~km})$ the percentage area of improved grassland (grazing land) and arable land were shown to be significantly higher in areas surrounding known roost locations. Previous studies have established the relationship between $E$. serotinus and grazing land by analysing the habitats visited by radiotracked bats or by linking prey fragments found in faecal pellets to the habitats in which they occur (e.g., [35, 38, 41, 43, 54]). However, such studies did not include spatial analysis or consider the distances between these habitats and roosts, but it was suggested that E. serotinus does not need specific habitat close to the roost as it will forage on whatever habitat is available [38]. The results presented in the current study may challenge this conclusion and suggest that there may be a preference for selecting roosting sites with access to habitats that support prey items. The conclusions of Kervyn and Libois [43] and Ransome [54] add further weight to this assertion and suggest that the absence of key-prey within close proximity of roosts results in bat species commuting greater distances, with a consequential decrease in fitness. It may be that $E$. serotinus bats select roosts close to arable land and grazing land or that the survival rates and relative fitness of E. serotinus is higher at these roost locations.

It is interesting to note, however, that despite the identification of significant differences in the larger buffers no significant differences were observed less than 500 metres from roosts. When similar studies were undertaken for other species of British bats this variability in the effects of distance was not found. In previous studies of other bat species it appears that habitats found to be significant at short distances (e.g., $<0.5 \mathrm{~km}$ ) from roosts were also found to be significant at greater distances (e.g., $>1.0 \mathrm{~km}$ ) [23, 25]. Our findings may reflect the more generalist foraging behaviour of $E$. serotinus. Generalist foraging behaviour suggests a diverse habitat matrix may be important to ensure an abundant prey base throughout the feeding season. Moreover, several studies have reported seasonal variations in the diet of $E$. serotinus, with analysis of faecal pellets showing that different preys are taken at different times of the year, depending on the abundance of the prey species [34, 35, 38, 43]. Early in the season E. serotinus moves between habitats that provide Diptera, Coleoptera, and Lepidoptera, before becoming dependent upon dung beetles Aphodius spp. in late summer [38]. Aphodius spp. are closely associated with cattle-dung and grazed land. Similar seasonal variations were reported in a radio tracking study by Robinson and Stebbings [34], with woodland being the most important habitat in a concentrated period during May, June, and July. Later in the year woodland became less used and was superseded as the main forage habitat by grazing land in August, September, and October. By October $100 \%$ of E. serotinus activity was assigned to grazing land.

Our analysis of woodland fragments in the areas surrounding roosts provided less than clear results (Table 3 ). No significant results were observed in the $0-0.5 \mathrm{~km}$ range, whilst a highly significant result was found for the number of woodland patches at $0.5-1.5 \mathrm{~km}$. Analysis showed that significantly more woodland patches were found in areas surrounding roosts.

Interestingly in the $1.5-4.5 \mathrm{~km}$ buffer zones there was a contrasting picture, with significantly fewer woodland patches in areas surrounding roosts. Yet, it is important to note that the woodland that was present was significantly clustered (Table 3; average nearest neighbour ratio $=0.86$ ). The pattern observed is perhaps unclear, but higher numbers of or 
densities of woodland patches may indicate the importance of small woodland patches as either linear features or connecting habitats.

Boughey et al. [31] found that small woodland patches were important for the soprano pipistrelle Pipistrellus pygmaeus but not for E. serotinus. Also to this effect, Bright [55] suggests that habitat generalist bat species are less likely to be influenced by the effects of habitat fragmentation. It may be that the current study suggests that the effects of habitat fragmentation may be scale dependent and indicate an area for further investigation.

Urban land was another land use type that showed inconsistent results. At the larger $1.5-4.5 \mathrm{~km}$ buffer distance, there was significantly more urban land surrounding controls compared to roosts. This significant difference was not found in other distance buffers, possibly offering further support to the notion that the effects of landscape pattern are scale dependent and that a diverse habitat matrix is required.

It is however important to recognise that while E. serotinus is known to concentrate foraging within $4.5 \mathrm{~km}$ of the roost [38], it is likely that a smaller proportion of this total area is actually visited and used. On average only 2-3 forage sites are visited per night $[34,38]$, and although a number of different sites will be used throughout the season $[34,35$, 38,43 ] the bat is unlikely to forage over the entire forage area. Therefore within the larger buffer zones there is the likelihood that although all the area is within the forage range, a large percentage of the area being analysed is not used by the bat. Total habitat composition perhaps becomes less important as long as a number of suitable forage habitats are available, ideally within a concentrated area. This would suggest that at larger distances from the roost, the availability of sufficient patches of quality foraging habitat with abundant prey base, is more important than the habitat composition as a whole.

4.4. Land Use at Roost Hotspots. It has yet to be established whether a roost is selected predominantly for its internal characteristics, with the bat then adapting its diet to the habitat surrounding the roost. On the contrary suitable forage areas may be first selected and then a roost nearby located; or perhaps a combination of both is considered. The results presented in the previous section do not necessarily answer these questions, but they do suggest that the surrounding habitat is an important factor in roost selection. In an attempt to further address these questions, pertaining to roost selection and landscape characteristics, density and hotspot analysis were undertaken. Kernel density analysis presented the opportunity to examine the landscape properties within areas identified as representative of centres of bat activity.

Centres of bat activity were determined using kernel density surfaces and the selection of the upper quartile zones (Q4). Results showed that significantly less percentage cover of coniferous woodland was found in roost hotspots (Q4) when compared to areas of low roost density (Q1). This pattern was also reflected in the fact that significantly fewer patches of coniferous woodland were found in density hotspot areas (see Table 4). This observation relates well to previous studies that have found little evidence of bat foraging in coniferous woodlands [27-29]. Furthermore, woodlands have consistently been associated with E. serotinus activity $[21,22,34]$, and this may be reflected in the high percentage of total woodland found in this study (Q4 $=22.1 \%$ total woodland cover). However this was not significantly following the application of Bonferroni's correction for multiple comparisons (Table 4). The Sussex region, and in particular the Weald, is widely recognised as an area that supports a considerable amount and variety of woodland at a national level and it may be that high levels of woodland are in general present throughout this particular landscape area [56].

The effects of fragmentation of woodland patches upon bats in the UK are unclear $[22,57]$, and the results presented in the current study do little to add clarity. FuentesMontemayor et al. [58] found that $P$. pipistrellus and $P$. pygmaeus activity was greater where distance between woodlands was lower, suggesting that clustered woodland distributions are preferred. While large woodland areas may be important for woodland roosting bats, patch area may not be important for E. serotinus, for whom the main function of woodland is perhaps to use woodland edge as a linear feature for commuting [40], with little evidence of extensive foraging within woodland interior (e.g., [21, 22, 34, 38]). The ambiguous relationship observed between woodland and individual roost location suggests that further research is required.

The number of patches of urban land was significantly higher in areas of low roost density compared to roost hotspots. Catto et al. [38] report that areas around streetlamps are the second most visited forage area; the species is most commonly associated with rural areas. Furthermore the study by Catto et al. [38] tracked bats from two roosts, both of which were in urban settings, and therefore the findings may be an example of the opportunist nature of the bat, rather than being a reflection of the importance of urban features for foraging.

Differences between results at hotspots, compared to the results for the habitat composition surrounding individual roosts, suggest that interactive factors may also influence roost selection. Robinson and Stebbings [34] suggest that when separate colonies are located close to one another, E. serotinus may be unable to expand its range due to competition from the other colonies. Therefore in areas of high roost density $E$. serotinus may be restricted to smaller home ranges and adapt to the prey available within a smaller radius.

\section{Conclusion}

Roost location is widely recognised to be a key factor in determining the survival and fitness of British bats. The current study demonstrates that E. serotinus roosts have a clustered distribution and infers that this species is selective with respect to roost location. The current study demonstrates that there are a number of significant differences between the landscape composition surrounding roost sites and that differences are evident only at particular scales. E. serotinus roost sites are located in areas with significantly higher cover of arable land and improved grassland (grazing land). Yet the composition of the landscape surrounding bat roost sites 
is not formally recognised in current protective legislation surrounding bats. Despite a less clear picture, woodland is also shown to be an important landscape component, with clustered woodland patches perhaps acting as important landscape features.

Kernel density analysis successfully provided an alternative method to examine the landscape structure and composition around roost sites and identified the location and characteristics of possible centres of bat activity in Sussex. Density analysis indicated that areas of high bat density had significantly less coniferous woodland cover and few patches of coniferous woodland and urban land, than areas of comparative low bat density. British bats and their roosts are protected by UK legislation; however, protection is not extended to foraging sites. This may indeed leave bats vulnerable to landscape change as roost sites are shown to relate to particular landscape characteristics.

\section{Conflict of Interests}

The author declares that there is no conflict of interests regarding the publication of this paper.

\section{Acknowledgments}

The authors would like to thank Sussex Biodiversity Record Centre and Sussex Bat Group for supplying bat roost data for East \& West Sussex. Land Cover Map 2000 data was supplied by the Centre for Ecology and Hydrology (CEH). The research was partly funded by the School of the Environment, University of Brighton.

\section{References}

[1] A. L. Walsh and S. Harris, "Foraging habitat preferences of vespertilionid bats in Britain," Journal of Applied Ecology, vol. 33, no. 3, pp. 508-518, 1996.

[2] P. A. Racey, "The ecology of European bats in relation to their conservation," in Bat Biology and Conservation, T. H. Kunz and P. A. Racey, Eds., pp. 247-260, Smithsonian Institution Press, Washington, DC, USA, 1998.

[3] J. M. Russ and W. I. Montgomery, "Habitat associations of bats in Northern Ireland: implications for conservation," Biological Conservation, vol. 108, no. 1, pp. 49-58, 2002.

[4] J. E. Duchamp and R. K. Swihart, "Shifts in bat community structure related to evolved traits and features of human-altered landscapes," Landscape Ecology, vol. 23, no. 7, pp. 849-860, 2008.

[5] S. Harris, P. Morris, S. Wray, and D. W. Yalden, A Review of Bristish Mammals: Population Estimates and Conservation Status of British Mammals and Other Cetaceans, Joint Nature Conservation Committee, Peterborough, UK, 1995.

[6] A. M. Hutson, S. Mickleburgh, and P. A. Racey, Microchiropteran Bats: Global Status Survey and Conservation Action Plan, IUCN/SSC Chiroptera Specialist Group, IUCN, Cambridge, UK, 2001 .

[7] E. F. Connor, A. C. Courtney, and J. M. Yoder, "Individuals-area relationships: The relationship between animal population density and area," Ecology, vol. 81, no. 3, pp. 734-748, 2000.
[8] N. Vaughan, G. Jones, and S. Harris, "Habitat use by bats (Chiroptera) assessed by means of a broad-band acoustic method," Journal of Applied Ecology, vol. 34, no. 3, pp. 716-730, 1997.

[9] A. M. Hutson, Action Plan for the Conservation of Bats in the United Kingdom, The Bat Conservation Trust, London, UK, 1993.

[10] M. B. Fenton, "Science and the conservation of bats," Journal of Mammalogy, vol. 78, no. 1, pp. 1-14, 1997.

[11] Millennium Ecosystem Assessment, Ecosystems and Human Well Being: Biodiversity Synthesis, World Resources Institute, Washington, DC, USA, 2005.

[12] N. G. Burnside, R. F. Smith, and S. Waite, "Recent historical land use change on the South Downs, United Kingdom," Environmental Conservation, vol. 30, no. 1, pp. 52-60, 2003.

[13] R. L. Burgess and D. M. Sharpe, Forest Island Dynamics in ManDominated Landscapes, Springer, New York, NY, USA, 1981.

[14] S. P. Mickleburgh, A. M. Hutson, and P. A. Racey, "A review of the global conservation status of bats," Oryx, vol. 36, no. 1, pp. 18-34, 2002.

[15] P. F. Donald and A. D. Evans, "Habitat connectivity and matrix restoration: the wider implications of agri-environment schemes," Journal of Applied Ecology, vol. 43, no. 2, pp. 209-218, 2006.

[16] D. Kleijn, R. A. Baquero, Y. Clough et al., "Mixed biodiversity benefits of agri-environment schemes in five European countries," Ecology Letters, vol. 9, no. 3, pp. 243-254, 2006.

[17] M. B. Fenton and I. L. Rautenbach, "Impacts of ignorance and human and elephant populations on the conservation of bats in African woodlands," in Bat Biology and Conservation, T. H. Kunz and P. A. Racey, Eds., pp. 261-270, Smithsonian Institution Press, Washington, DC, USA, 1998.

[18] G. Kerth, K. Weissmann, and B. König, "Day roost selection in female Bechstein's bats (Myotis bechsteinii): a field experiment to determine the influence of roost temperature," Oecologia, vol. 126, no. 1, pp. 1-9, 2001.

[19] Z. Bihari, "The roost preference of Nyctalus noctula (Chiroptera, Vespertilionidae) in summer and the ecological background of their urbanization," Mammalia, vol. 68, no. 4, pp. 329-336, 2004.

[20] T. H. Kunz, "Roosting ecology," in Ecology of Bats, T. H. Kunz, Ed., pp. 1-55, Plenum Press, New York, NY, USA, 1982.

[21] J. Battersby, A comparison of the roost ecology of the brown longeared bat Plecotus auritus and the serotine bat Eptesicus serotinus [Ph.D. thesis], University of Sussex, 1999.

[22] K. L. Boughey, I. R. Lake, K. A. Haysom, and P. M. Dolman, "Effects of landscape-scale broadleaved woodland configuration and extent on roost location for six bat species across the UK," Biological Conservation, vol. 144, no. 9, pp. 2300-2310, 2011.

[23] A. C. Entwistle, P. A. Racey, and J. R. Speakman, "Roost selection by the brown long-eared bat Plecotus auritus," Journal of Applied Ecology, vol. 34, no. 2, pp. 399-408, 1997.

[24] C. Moussy, "Selection of old stone buildings as summer day roost by the brown long-eared bat Plecotus auritus," Acta Chiropterologica, vol. 13, no. 1, pp. 101-111, 2011.

[25] E. V. Jenkins, T. Laine, S. E. Morgan, K. R. Cole, and J. R. Speakman, "Roost selection in the pipistrelle bat, Pipistrellus pipistrellus (Chiroptera: Vespertilionidae), in northeast Scotland," Animal Behaviour, vol. 56, no. 4, pp. 909-917, 1998.

[26] S. F. Oakeley and G. Jones, "Habitat around maternity roosts of the $55 \mathrm{kHz}$ phonic type of pipistrelle bats (Pipistrellus pipistrellus)," Journal of Zoology, vol. 245, no. 2, pp. 222-228, 1998. 
[27] D. Russo and G. Jones, "Use of foraging habitats by bats in a Mediterranean area determined by acoustic surveys: conservation implications," Ecography, vol. 26, no. 2, pp. 197-209, 2003.

[28] D. Russo, G. Jones, and A. Migliozzi, "Habitat selection by the Mediterranean horseshoe bat, Rhinolophus euryale (Chiroptera: Rhinolophidae) in a rural area of southern Italy and implications for conservation," Biological Conservation, vol. 107, no. 1, pp. 71-81, 2002.

[29] P. G. Smith and P. A. Racey, "Natterer's bats prefer foraging in broad-leaved woodlands and river corridors," Journal of Zoology, vol. 275, no. 3, pp. 314-322, 2008.

[30] N. C. Downs and P. A. Racey, "The use by bats of habitat features in mixed farmland in Scotland," Acta Chiropterologica, vol. 8, no. 1, pp. 169-185, 2006.

[31] K. L. Boughey, I. R. Lake, K. A. Haysom, and P. M. Dolman, "Improving the biodiversity benefits of hedgerows: how physical characteristics and the proximity of foraging habitat affect the use of linear features by bats," Biological Conservation, vol. 144, no. 6, pp. 1790-1798, 2011.

[32] A. M. Hutson, "Eptesicus serotinus," in Mammals of the British Isles, S. Harris and D. Yalden, Eds., pp. 356-360, The Mammal Society, Southampton, UK, 4th edition, 2008.

[33] C. Dietz, O. von Helversenand, and D. Nill, Bats of Britain, Europe and Northwest Africa, A \& C Black, London, UK, 2009.

[34] M. F. Robinson and R. E. Stebbings, "Home range and habitat use by the serotine bat, Eptesicus serotinus, in England," Journal of Zoology, vol. 243, no. 1, pp. 117-136, 1997.

[35] C. M. Catto, A. M. Hutson, and P. A. Racey, "The diet of Eptesicus serotinus in southern England," Folia Zoologica, vol. 43, no. 4, pp. 307-314, 1994.

[36] C. Harbusch, Aspects of the ecology of serotine bats (Eptesicus serotinus) in contrasting landscapes in southwest Germany and Luxembourg [Ph.D. thesis], University of Aberdeen, 2003.

[37] A. L. Walsh and B. A. Mayle, "Bat activity in different habitats in a mixed lowland woodland," Myotis, vol. 29, pp. 97-104, 1991.

[38] C. M. C. Catto, A. M. Hotson, P. A. Racey, and P. J. Stephenson, "Foraging behaviour and habitat use of the serotine bat (Eptesicus serotinus) in southern England," Journal of Zoology, vol. 238, no. 4, pp. 623-633, 1996.

[39] T. Bartonička and J. Zukal, "Flight activity and habitat use of four bat species in a small town revealed by bat detectors," Folia Zoologica, vol. 52, no. 2, pp. 155-166, 2003.

[40] B. Verboom and H. Huitema, "The importance of linear landscape elements for the pipistrelle Pipistrellus pipistrellus and the serotine bat Eptesicus serotinus," Landscape Ecology, vol. 12, no. 2, pp. 117-125, 1997.

[41] M. F. Robinson and R. E. Stebbings, "Food of the serotine bat, Eptesicus serotinus-is faecal analysis a valid qualitative and quantitative technique?" Journal of Zoology, vol. 231, no. 2, pp. 239-248, 1993.

[42] G. Brandt, L. Blows, D. Linton, N. Paling, and C. Prescott, "Habitat associations of British bat species on lowland farmland within the Upper Thames catchment area," Centre For Wildlife Assessment \& Conservation E-Journal, vol. 1, pp. 10-19, 2007.

[43] T. Kervyn and R. Libois, "The diet of the serotine bat. A comparison between rural and urban environments," Belgian Journal of Zoology, vol. 138, no. 1, pp. 41-49, 2008.

[44] R. M. Fuller, G. M. Smith, J. M. Sanderson et al., Countryside Survey 2000 Module 7. Land Cover Map 2000: A Guide To the Classification System, CEH, Huntingdon, UK, 2002.
[45] H. L. Beyer, "Hawth's analysis tools for ArcGIS," 2004, http:// www.spatialecology.com/htools/.

[46] T. C. Bailey and A. C. Gatrell, Interactive Spatial Data Analysis, Longman Group, Harlow, UK, 1995.

[47] D. Williamson, S. McLafferty, V. Goldsmith, J. Mollenkopf, and P. McGuire, "A better method to smooth crime incident data," ESRI ArcUser Magazine, 1999, http://esri.com/news/ arcuser/0199/crimedata.html.

[48] A. Fotheringham, C. Bunsden, and M. Charlton, Quantitative Geography, Sage, London, UK, 2000.

[49] Google Map, “Google Maps,” London, UK, 2010, http://maps .google.co.uk/.

[50] S. Waite, Statistical Ecology in Practice, A Guide to Analysing Environmental and Ecological Field Data, Pearson Education, London, UK, 2000.

[51] A. L. Walsh, R. E. Stebbings, and M. J. A. Thompson, "Distribution and abundance of the pipistrelle bat Pipistrellus pipistrellus," Annual Report, Vincent Wildlife Trust, 1988.

[52] J. R. Speakman, P. A. Racey, C. M. C. Catto, P. I. Webb, S. M. Swift, and A. M. Burnett, "Minimum summer populations and densities of bats in NE Scotland, near the northern borders of their distributions," Journal of Zoology, vol. 225, no. 2, pp. 327$345,1991$.

[53] A. C. Entwistle, P. A. Racey, and J. R. Speakman, "Social and population structure of a gleaning bat, Plecotus auritus," Journal of Zoology, vol. 252, no. 1, pp. 11-17, 2000.

[54] R. D. Ransome, "The management of feeding areas for the greater horseshoe bats," English Nature Research Reports, vol. 174, pp. 1-74, 1996.

[55] P. W. Bright, "Habitat fragmentation-problems and predictions for British mammals," Mammal Review, vol. 23, pp. 101-111, 1993.

[56] N. G. Burnside, D. J. Metcalfe, R. F. Smith, and S. Waite, "Ghyll woodlands of the Weald: characterisation and conservation," Biodiversity and Conservation, vol. 15, no. 4, pp. 1319-1338, 2006.

[57] G. Lesiński, M. Kowalski, B. Wojtowicz, J. Gulatowska, and A. Lisowska, "Bats on forest islands of different size in an agricultural landscape," Folia Zoologica, vol. 56, no. 2, pp. 153-161, 2007.

[58] E. Fuentes-Montemayor, D. Goulson, and K. J. Park, "Pipistrelle bats and their prey do not benefit from four widely applied agrienvironment management prescriptions," Biological Conservation, vol. 144, no. 9, pp. 2233-2246, 2011. 

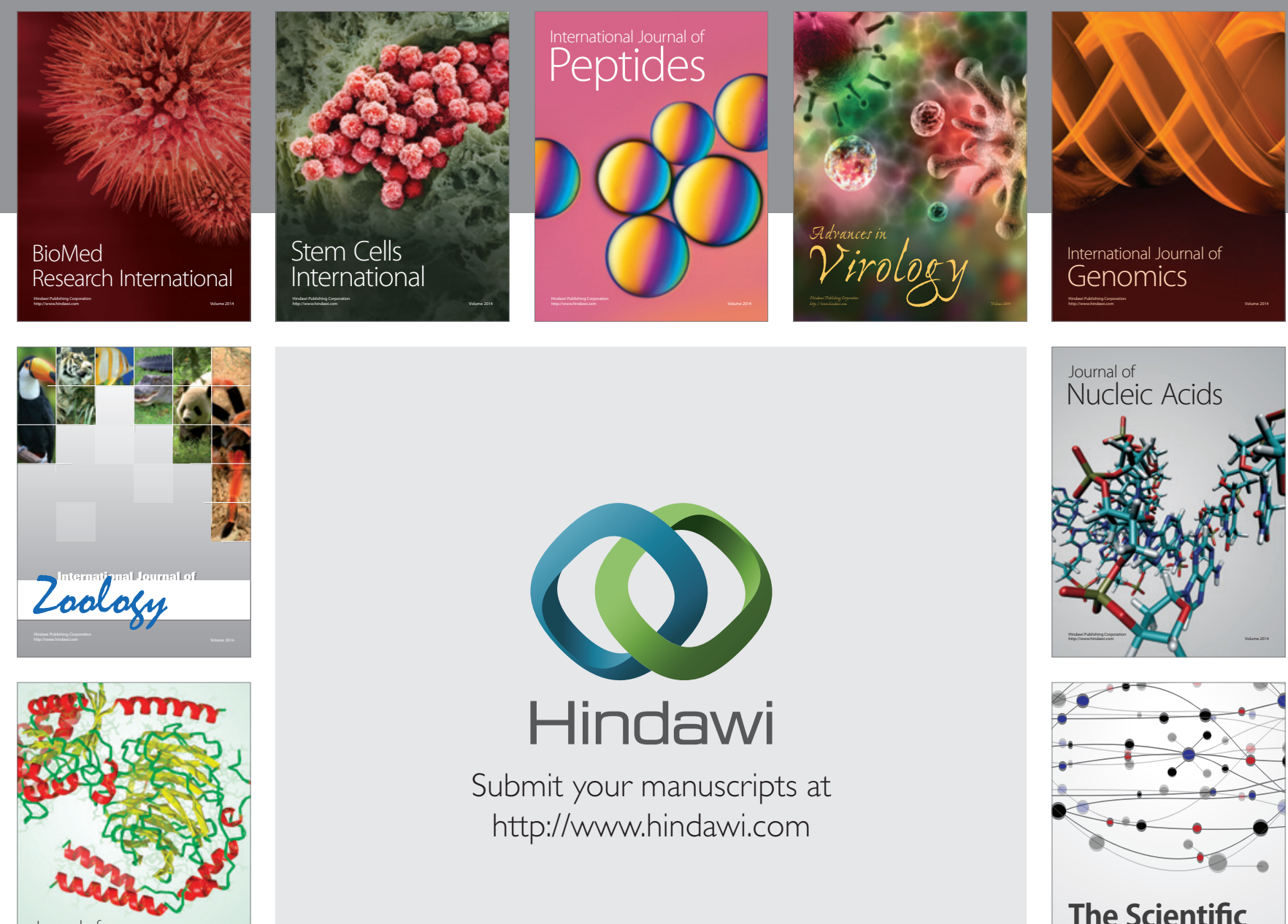

Submit your manuscripts at

http://www.hindawi.com

Journal of
Signal Transduction
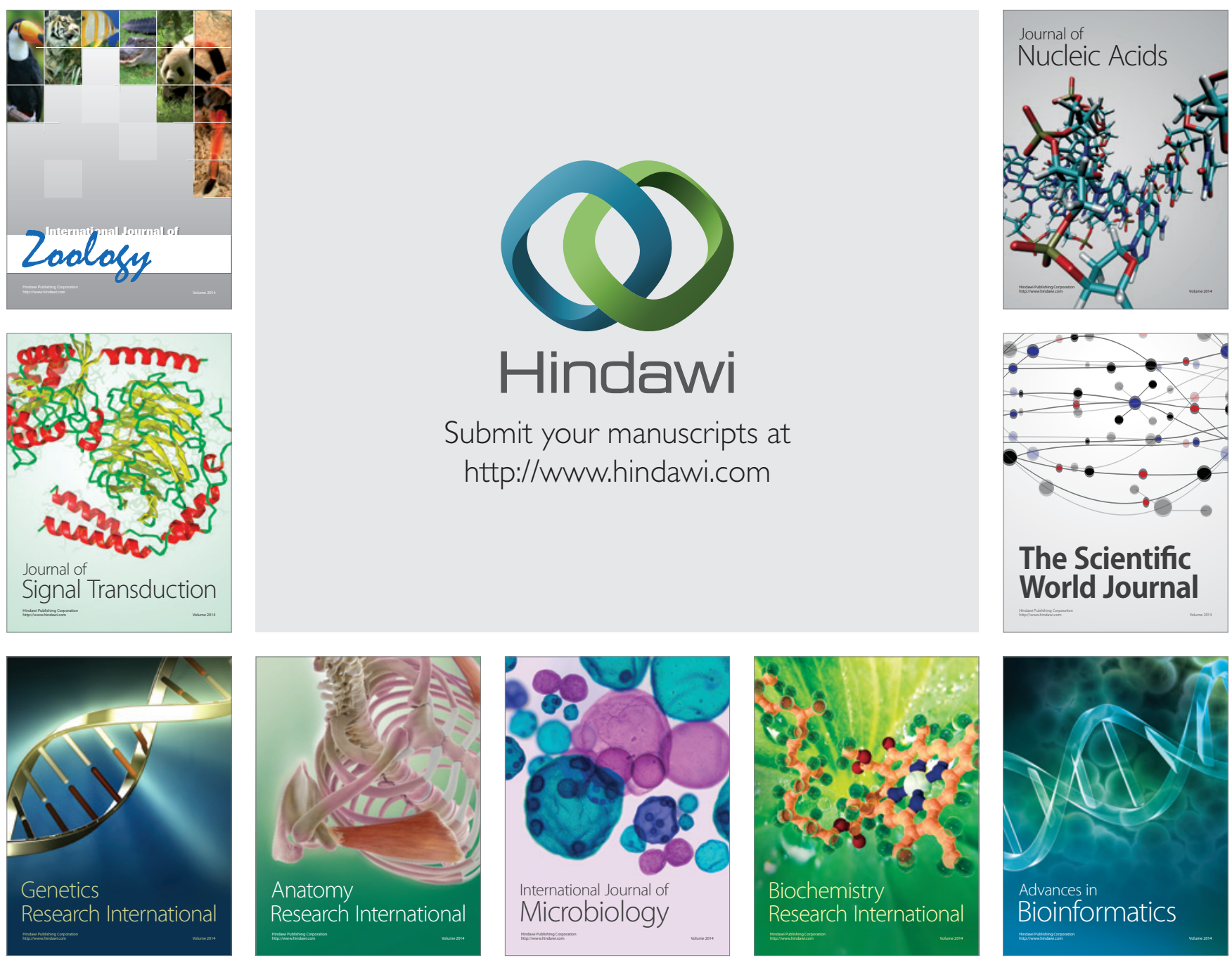

The Scientific World Journal
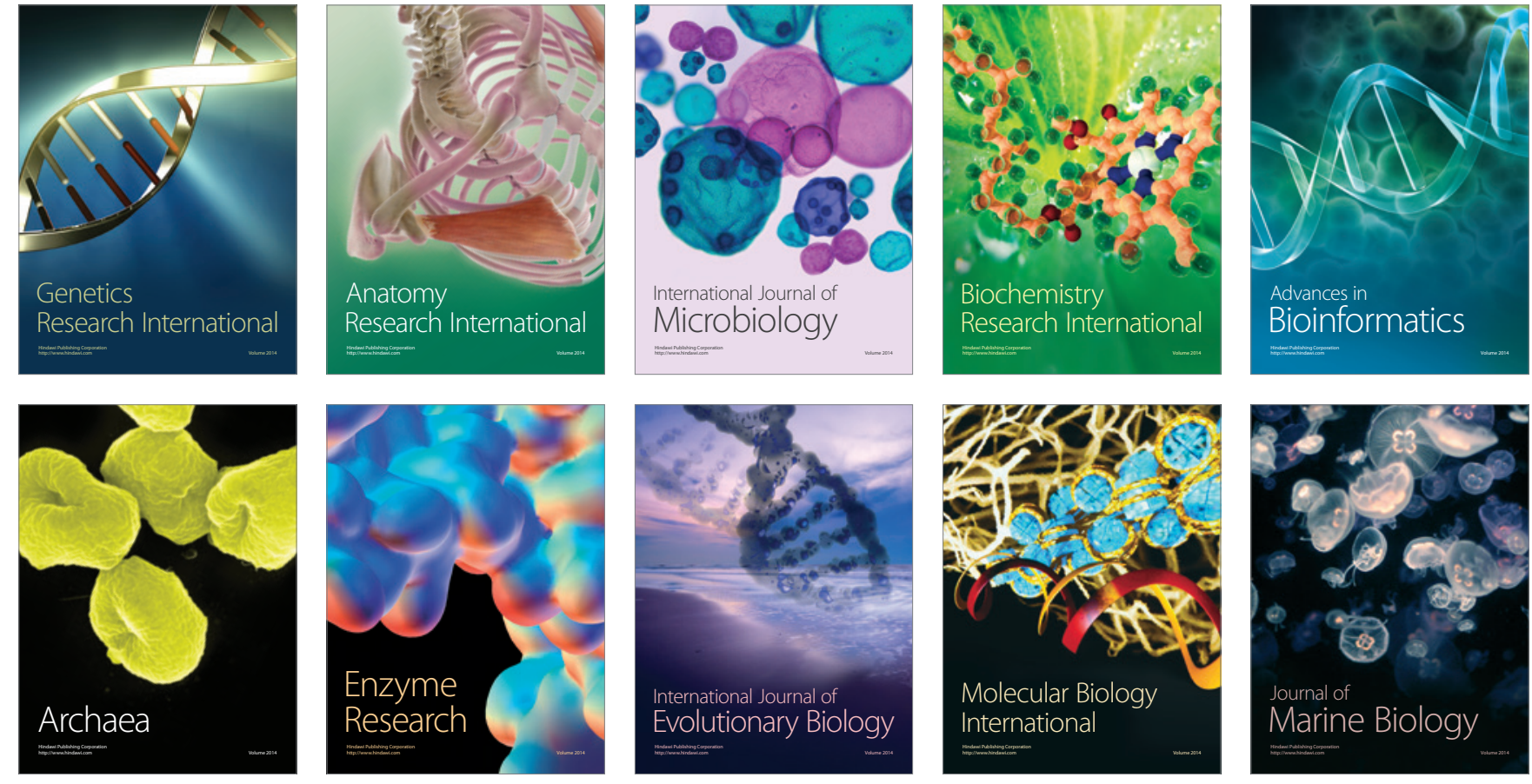